\title{
The contribution of RCTs to quality management and their feasibility in practice
}

\author{
Jens Ivar Brox
}

Received: 22 December 2008/Revised: 1 April 2009/ Accepted: 15 April 2009/Published online: 1 May 2009

(C) The Author(s) 2009. This article is published with open access at Springerlink.com

\begin{abstract}
The randomized controlled trial (RCT) is generally accepted as the most reliable method of conducting clinical research. To obtain an unbiased evaluation of the effectiveness of spine surgery, patients should be randomly assigned to either new or standard treatment. The aim of the present article is to provide a short overview of the advantages and challenges of RCTs and to present a summary of the conclusions of the Cochrane Reviews in spine surgery and later published trials in order to evaluate their contribution to quality management and feasibility in practice. From the searches, 130 RCTs were included, 95 from Cochrane Reviews and systematic reviews, and 35 from additional search. No study comparing surgery with sham surgery was identified. The first RCT in spine surgery was published in 1974 and compared debridement and ambulatory treatment in tuberculosis of the spine. The contribution of RCTs in spinal surgery has markedly increased over the last 10 years, which indicates that RCTs are feasible in this field. The results demonstrate missing quality specifications. Despite the number of published trials there is conflicting or limited evidence to support various techniques of instrumentation. The only intervention that receives strong evidence is discectomy for faster relief in carefully selected patients due to lumbar disc prolapse with sciatica. For future trials, authors, referees, and editors are recommended to follow the CONSORT statement. RCTs provide evidence to support clinical
\end{abstract}

\section{J. I. Brox $(\bowtie)$}

Section for Back Surgery and Physical Medicine and Rehabilitation, Orthopaedic Department,

Rikshospitalet Medical Centre, University of Oslo,

Rikshospitalet, Sognsvannsveien, 0027 Oslo, Norway

e-mail: jens.ivar.brox@rikshospitalet.no opinions before implementation of new techniques, but the individual clinical experience is still important for the doctor who has to face the patient.

Keywords Spine surgery - Randomized controlled trial · Quality management · CONSORT statement · Review

\section{Introduction}

The placebo effect in surgery should not be underestimated leaving a rationale for conducting randomized clinical trials to evaluate the treatment effectiveness of spinal surgery. In a short note, JH Baron, honorary professional lecturer at Mount Sinai School of Medicine, New York, reminds us to never underestimate placebo:

When I became a clinical student in 1952 medical wards had many patients with incurable chronic rheumatic heart disease. Mitral valv(ul)otomy had just started, and at the Central Middelsex Hospital Dr. Keith Ball presented an outpatient who had been operated on. "It was a miracle for me, and once a cripple I can now breathe and walk adequately," and she then showed us what she could do. After she had gone Dr. Ball explained that when the surgeon put his finger in the left atrium the mitral valve was so tight and hard that the stenosis was uncorrectable.

I learnt three lessons, which helped to make me a competent clinician. First, accept calmly praise (or blame) from a patient, but know in your conscience that you may not have been responsible, because, second, although the public may, you must not confuse sequence and consequence-post hoc, non-ergo propter hoc. Third, never underestimate or denigrate 
the tremendous efficacy of a placebo, especially a dramatic procedure such as an operation. Fortunately in 1952, I was also taught by Richard Doll and Francis Avery Jones, who were putting controlled clinical trials into main-stream British medicine and providing evidence to replace "in my experience" [5].

The evaluation of possible improvements of surgical treatment of spinal disorders has historically been insufficient. In recent years it has become widely recognized that properly conducted trials, which follow the principles of scientific experiments, provide a reliable platform in the evaluation of treatment efficacy and safety [55]. One of the essential characteristics of clinical trials is that results from limited sample of patients are used to make inferences about which treatment that should be recommended for the general population of patients in the future. In clinical practice, spine surgeons often make inferences about treatment from experiences of success in single cases. Since several factors such as biological variation and the treatment expectancy in patients with the same condition will show varied responses to the same treatment, groups of patients are required. Retrospective studies contain serious potential biases, such as observer and selection bias, that will influence results. The effectiveness of a new surgical treatment should be compared prospectively with a control group of similar patients receiving standard treatment. Although the great majority of clinical trials have been concerned with drug therapy within the pharmaceutical industry, over the last 25 years such trials have been accepted as the golden standard for evaluation of the effectiveness of spine surgery.

The first clinical trial was published by Lind [38] and evaluated treatments of scurvy, while the first clinical trial with a properly randomized control group was for the treatment of pulmonary tuberculosis in 1948 [44]. The randomized controlled trial (RCT) is generally accepted as the most reliable method of conducting clinical research. To obtain an unbiased evaluation of the effectiveness of spinal surgery, patients should be randomly assigned to either new or standard treatment. The first RCT in spinal surgery was published in 1974 and compared debridement and ambulatory treatment in the management of tuberculosis of the spine [45]. Today uniform recommendations are given for purpose, design, conduction, analysis, and reporting of clinical trials [47]. The aim of this article is first to briefly describe these elements, then to update the latest published Cochrane Reviews on spinal surgery to report the contribution of RCTs in spinal surgery, and finally to discuss the feasibility of RCTs in this field.

\section{Main elements of RCTs}

\section{Purpose}

A general concept or background is essential preliminary for a worthwhile clinical trial. This is particularly challenging for trials comparing spinal surgery with non-surgical treatment because surgery is commonly believed to be more effective both in the general population, among patients, and surgeons. Precise specific hypotheses must be defined for properly planning of a trial. Four basic issues concern the precise definition of patients eligible for the study, the need for and the choice of comparison group, description of the treatments compared, primary and secondary end-points or outcome variables, and time for evaluation.

\section{Design}

A written protocol is essential in the planning of a trial. Registration of the protocol is required for publication, and different registers are available. The number of patients needed should be estimated to provide reasonable knowledge about whether the trial is feasible at all, at one surgical department or require a multi-centre organization. A person or a unit independent from those who run the trial should conduct the randomization. Each patient should have a 50/50 chance to be assigned to either treatment and allocation should be concealed. Double-blind design is not available for comparison of surgical and non-surgical treatment unless sham surgery is either combined with the latter or included to compare placebo and surgery. It is generally considered to be unethical to subject a control group to an incision under anaesthetic to mimic genuine surgery. This is a controversial issue because the distorting influences of uncontrolled trials may include implementation of surgery at the benefit from the placebo response. In 1972, Chalmers [11] argued that randomization is introduced infrequently and to late to evaluate new operations. He referred to 152 trials of operative therapy for coronary heart disease of which only two were randomized and found litigation of the internal mammary artery of no value. For comparison of two different surgical methods double-blind design offers an unbiased feasible alternative and should be regarded as the golden standard.

\section{Conduct of the trial}

Informed written consent should be obtained from all included patients. Those who are not willing to accept one of the treatment options should not be included. Such patients are more likely to withdraw from the trial, which 
makes it difficult to draw firm conclusions from the randomized sample of patients. Although patients according to the Helsinki declaration are allowed to withdraw from the study at any time without any explanation, a high number of withdrawals suggest poor conduct of the trial. It is essential that withdrawals should be treated as ordinary patients and given the best standard treatment available. For multi-centre trials a steering committee should monitor study entry, withdrawals, and supervise data collection prior to statistical analysis.

\section{Data analysis}

The intention to treat principle is a pragmatic approach requiring that all eligible patients, regardless of compliance with the protocol, should be included in the analysis. Sackett illustrated the importance of including withdrawals in 1981 by referring to a study comparing surgical versus medical therapy for bilateral carotid stenosis [18]. By including surgical patients who died before leaving the hospital results were reversed.

Sometimes withdrawn patients can be included in some parts of the analysis, but not in others. A patient with a major complication, by example lower limb amputation caused by vascular injury in disc prosthesis surgery, may withdraw and subsequently provide important information for costs and complications, but lack response data for disability and pain that are often used as primary endpoints. Preferably multiple imputation techniques, or more biased methods such as carry-forward the last available value or inserting the worst possible value should replace lack of response data. In any case handling of lack of response data should be precisely reported and in general analyses using different values of missing data may add valuable information about the consistency and robustness of results.

\section{Reporting}

The flow-chart informs the reader about the conduction of the trial. The number of patients recruited, reasons for being included, the number who received the treatment they were allocated to, withdrawals and cross-overs, and the number included in the main analyses, should be listed. In general hypotheses testing should be restricted to outcome and not be applied to compare baseline characteristics in the groups being compared. Significance tests are used to infer whether the observed differences are genuine, but should be followed by estimates of the magnitude of the differences including confidence limits. The main purpose of a clinical trial should be to estimate the size of the treatment effect for the primary outcome of the new treatment compared with the standard treatment. The whole idea of confidence limits is to give some idea what the true value or treatment effect in future patients might be.

\section{Methods}

The latest published Cochrane Reviews on spinal surgery performed the basis for inclusion of trials to evaluate the contribution of RCTs in spine surgery [19, 20, 29, 73]. An updated search on Medline was performed combining the text strategy outlined in these reviews with "spinal infection", "postoperative infection", "vertebral fracture", "osteoporotic fracture", "compression fracture", "spinal tumour", "spinal metastasis", "spinal deformity", and "scoliosis*" up to July 2008. Additional studies were identified from personal knowledge of the literature. The inclusion of trials was not restricted to any particular outcome variable. RCTs that had follow-up of at least 6 months and were published in English were included. Neck surgery was not included. Systematic quality assessment of the studies included in the Cochrane Reviews was considered to be beyond the scope of the present article, and the quality assessment of studies from the updated review was limited to evaluation of the reporting of number of patients lost to follow up, concealed allocation, flow chart, intention to treat, and confidence intervals. The quality of concealment allocation was interpreted according to Gibson and Waddell [19] in 3 grades: A, clearly yes is some form of centralized randomization scheme or assignment system; B, unclear, assignment envelopes, a "list" or "table", evidence of possible randomization failure such as markedly unequal control and trial groups, or trials stated to be random but with no description; C, clearly no, alternation, case numbers, dates of birth, or any other such approach, allocation procedures that were transparent before assignment. In tables, $\mathrm{A}$ is tabulated as yes (concealed allocation) and $\mathrm{B}$ and $\mathrm{C}$ as no (unclear allocation). Outcome measures were not classified as success or failure, and no attempt was made to pool data for calculation of odds ratio for use in meta-analysis. A qualitative approach was used for evidence classification-strong evidence: generally consistent findings provided by (a systematic review of) multiple high-quality RCTs; moderate evidence: generally consistent findings provided by a systematic review of multiple (at least four) low-quality RCTs, or at least two highquality RCTs.; limited or conflicting evidence: one RCT (either of low or high quality) or inconsistent findings from (a systematic review of) muliple (at least four) RCTs; no evidence: no RCTs [1]. 
Fig. 1 Yearly rate of RCTs published in English in spinal surgery, excluding neck surgery

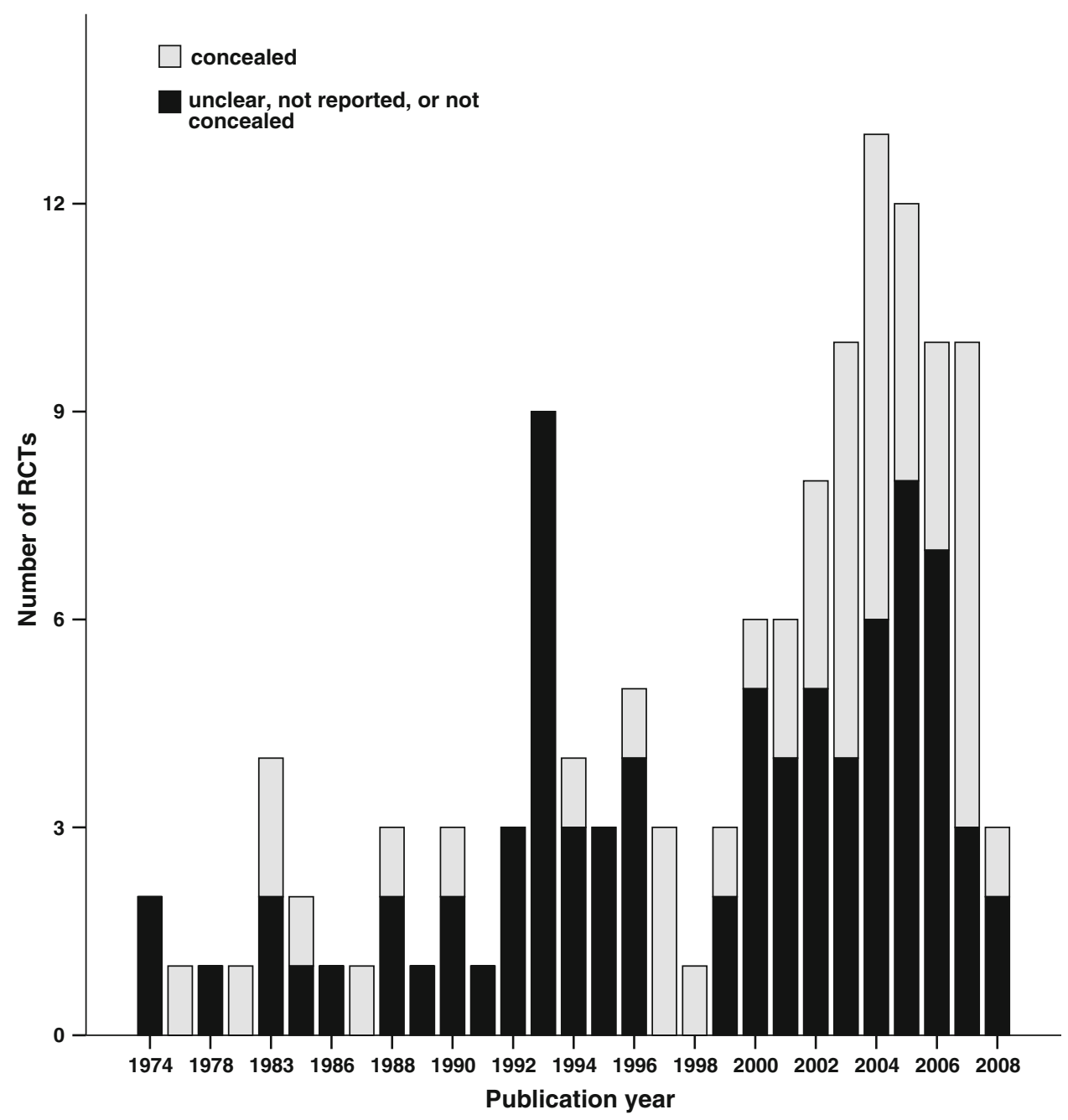

\section{Results}

All together 130 RCTs were included, 95 from Cochrane Reviews and systematic reviews, and 35 from additional searches. No study comparing spine surgery with sham surgery was identified. The latest published Cochrane Reviews reported on one trial comparing non-operative treatment for thoracolumbar burst fractures without neurological deficit [73], 31 trials on surgery for degenerative lumbar spondylosis including degenerative spondylolisthesis and spinal stenosis [19], 40 RCTs on surgical interventions for lumbar disc prolapse in patients with sciatica [20], and two trials on routine surgery in addition to chemotherapy for treating spinal tuberculosis [29]. In addition, three trials on spine surgery were included from a Cochrane Review on the effectiveness of wound suction drains in orthopaedic surgery [51], ten trials from a systematic review on bone growth factors [44]. Seven trials comparing radical surgery and debridement in tuberculosis, that were excluded from the Cochrane Review, are included in Fig. 1, but not in Table 2. Thirty-five additional trials were included (Table 2). In addition, four trials were identified and excluded: one on osteoporotic compression fractures because follow-up was 2 weeks [63]; one was a subgroup analysis of patients with degenerative spondylolisthesis in a previously published study on interspinous decompression by an implant in patients with neurogenic claudication [4]; one on instrumented posterior versus instrumented circumferential lumbar fusion in the treatment of lumbar stenosis with low degree lumbar spondylolisthesis was published in Chinese patients [16]; and one compared fusion and pseudarthrosis within an RCT [33]. Figure 1 illustrates the yearly rate of published RCTs and the number that reported concealed allocation.

\section{Lumbar disc herniation with radiculopathy}

Five additional trials that assessed the effectiveness of surgery in patients with disc prolapse and sciatica and published in eight papers were identified [25, 30, 50, 53, 54, 56, 61]. The Cochrane Review included four trials that compared discectomy with conservative treatment and two 
additional trials were identified [50, 54]. All trials had high methodological quality, although the number of crossovers ranged from $26 \%$ [65] to $39 \%$ [50, 54], and one trial had $50 \%$ withdrawals [70]. All trials favoured surgery, although one of the trials is inconclusive [70].

Based on the systematic review and two additional trials there is strong evidence that for carefully selected patients with sciatica due to lumbar disc prolapse, discectomy provides faster relief from the acute attack than conservative treatment. There is conflicting evidence about whether the difference is provided for longer than 6 months.

Three additional trials $[25,30,56]$ compared macro- and microdiscectomy and results are broadly similar with the conclusion from four trials in the Cochrane Review. Based on seven trials with variable methodological quality there is moderate evidence that macro- and microdiscectomy are equally effective.

The Cochrane Review concluded that the trials on percutaneous or laser discectomy do not provide evidence on the efficacy of these methods. The conclusion on laser discectomy is supported by one recent systematic review [22]. Including 16 RCTs and one quasi-RCT the Cochrane Review concluded that chemonucleolysis was less effective than discectomy and more effective than placebo. There were no additional trials that evaluated these methods.

Spinal stenosis and neurogenic claudication

The Cochrane Review included three trials in patients with no evidence of degenerative spondylolisthesis. Nine additional trials were identified [6, 9, 13, 14, 23, 35, 42, 60, 69]. This was a heterogeneous group of studies, including patients with signs and symptoms suggesting isolated nerve root stenosis or involvement of multiple levels. Table 2 presents two additional trials that compared surgical and non-operative treatment $[42,69]$. Results from these trials and two trials [3, 75] included in the Cochrane Review favoured surgery, and the difference was significant for subjective outcome in three of the trials [42, 69, 75]. Except from one trial that reported that the insertion of an interspinous device was effective for short- and long-term follow-up [32, 75, 76], the other trials evaluated the effectiveness of decompression. One high-quality trial reported effectiveness on back and leg pain, and disability, but not on self-reported and measured walking distance [42]. One large high-quality trial reported $37 \%$ withdrawals from surgery and $43 \%$ cross-overs from non-operative treatment, which makes a firm conclusion difficult [69]. Results according to the treatment received strongly favoured surgery.

Based on one systematic review and two additional RCTs there is moderate evidence that surgery is more effective than non-operative treatment on back and leg pain and disability, but not on walking ability, in patients with spinal stenosis and neurogenic claudication.

The Cohrane Review provided one trial that compared additional fusion with decompression alone [60] and four additional trials [9, 13, 23, 35] compared various surgical procedures. These trials provide moderate evidence that none of the procedures are more effective and limited evidence that net costs increase with the addition of instrumented fusion [23].

Spinal stenosis and neurogenic claudication and degenerative spondylolisthesis

The Cochrane Review reported on three trials that considered the role of adjunct fusion in spinal stenosis associated with single or two-level degenerative spondylolisthesis.

Table 3 presents two additional trials [17, 68]. One compared decompression and fusion with non-operative treatment and reported that although results favoured surgery, the effectiveness was not verified by intention-to-treat analysis [68]. Cross-overs and withdrawals were about $40 \%$.

The Cochrane Review concluded that the studies that compared fusion versus decompression alone provide limited evidence on the role of fusion. The additional studies provide limited evidence on the role of fusion compared with non-operative treatment and for unilateral versus bilateral instrumentation.

\section{CLBP and disc degeneration}

Five additional trials were identified [15, 31, 36, 43, 58]. Based on two small trials [7, 8] the Cochrane Review suggested that outcomes of fusion are not better than those of a modern rehabilitation approach. A recent large highquality trial [15] reported similar results (Table 2).

Accordingly, the three trials constitute moderate evidence that effectiveness of fusion is not better than intensive rehabilitation based on cognitive behavioural principles for improvement of disability, back pain, and return to work. This is in keeping with the conclusion of one recent systematic review [46] and one meta-analysis [26].

The Cochrane Review identified two trials on disc prosthesis. Later publications have reported on different outcome measures and longer follow-up in these trials. One additional trial reported early results from a subgroup in a larger multi-centre, but not yet published trial [59]. Results were in keeping with the Cochrane Review and do not permit a firm conclusion on the effectiveness of disc prosthesis. 
Table 1 Conclusions from the Cochrane Reviews

CLBP and disc degeneration (degenerative lumbar spondylosis): 31 trials published to April 2005

No conclusions are possible about relative effectiveness of anterior, posterior, or circumferential fusion. The preliminary results of three small trials of intradiscal electrotherapy suggest it is ineffective, except possibly in highly selected patients. Preliminary data from three trials of disc arthroplasty do not permit firm conclusions.

Lumbar disc prolapse and sciatica: 41 trials published to January 2007

Surgical discectomy for carefully selected patients due to lumbar disc prolapse provides faster relief from the acute attack than conservative management, although any positive or negative effects of the lifetime history of the underlying disc disease are still unclear. The evidence for other minimally invasive techniques remains unclear except for chemonucleolysis using chemopapain, which is no longer widely available.

Thoracolumbar burst fractures without neurological deficit: 1 trial published to May 2006

There was no statistically significant difference on the functional outcomes 2 years or more after therapy between operative and non-operative treatment for thoracolumbar burst fractures without neurological deficit. However, this review was able to include only one randomized controlled trial with a small sample size and poor quality, which precluded firm conclusions. More research with high-quality trials is needed.

Routine surgery in addition to chemotherapy for treating spinal tuberculosis: 2 trials published to September 2007

The two included trials had too few participants to be able to say whether routine surgery might help. Although current medication and operative techniques are now far more advanced, these results indicate that routine surgery cannot be recommended unless within the context of a large, well-conducted randomized trial. Clinicians may judge that surgery may be clinically indicated in some groups of patients. Future studies need to address these topics as well as the patient's view of their disease and treatment.

\section{Techniques of fusion}

The Cochrane Review identified 15 trials that addressed various questions about the role of instrumentation. This was a heterogeneous group of studies, including patients with different techniques and diagnoses. It was concluded that results were conflicting and do not permit conclusions about the relative effectiveness of anterior, posterior, and circumferential fusion. Ten additional trials were identified (Table 2). The results of these trials do not favour any particular method or instrumentation.

A systematic review included 11 trials on bone growth factors [48]. Two additional trials were included [14, 36]. The results were in agreement with the conclusion of the SR that the use of BMPs at the vertebrae can eliminate the need for surgery to harvest autologous bone, but that further RCTs of good methodological quality are adviseable so as to clarify the effectiveness of BMPs in clinical practice.

Based on 25 RCTs and in keeping with the Cochrane Review [19] and a later review [62], it is concluded that demanding fusion techniques are not better than traditional posterolateral fusion without instrumentation. Despite 13 trials including one SR, there is limited evidence for the clinical use of BMPs.

Thoracolumbar burst fractures without neurological compromise

Three additional RCTs evaluated various types of surgical methods [34, 64, 72]. Based on the results of the Cochrane Review and these studies there is limited evidence that posterior instrumented fusion is not better than conservative treatment including orthosis, and that a particular surgical method cannot be recommended.

Spinal infections and prophylaxis

The Cochrane Review [29] on routine surgery in addition to chemotherapy for treating spinal tuberculosis included two trials. No additional trials were identified. The limited evidence to support routine surgery reported in Table 1 is therefore not changed. The Cochrane Review excluded seven trials that compared radical resection of the tuberculos lesion and bone grafting with debridement, and these trials were not included.

Table 2 presents five trials on various interventions on prophylaxis of postoperative infections [10, 12, 28, 40,57]. Limited evidence is provided for the use of antibiotics [57], not to shave the skin [10], and for bactericidal wound irrigation in addition to antibiotics [12]. A Cochrane Review [51] concluded that there is moderate evidence not to use wound suction drains. Three trials on spine surgery were included in the Cochrane Review, and no effects on infection and haematoma were reported.

Based on these results there is moderate evidence not to use wound suction devices in routine spine surgery.

\section{Spinal metastasis}

One trial of low quality reported no additional effect of laminectomy to radiotherapy [52], but one trial of high quality reported additional effect of surgery including stabilization if deemed necessary [74]. Based on latest published trial, there is limited evidence that the addition of surgery is more effective than radiotherapy alone. 
Table 2 RCTs included from updated and supplementary search

\begin{tabular}{|c|c|c|c|}
\hline Study & Patients and intervention & Treatment effect & $\begin{array}{l}\text { Quality rating } \\
\text { (concealed allocation, } \\
\text { flow chart, intention } \\
\text { to treat, } 95 \% \mathrm{CI} \text { ) }\end{array}$ \\
\hline
\end{tabular}

\footnotetext{
Disc herniation and sciatica

Katayama [30], Japan Macrodiscectomy (I) versus

$(n=119)$

Hoogland [25], Germany

$(n=280)$

microdiscectomy (C)

Microdiscectomy and chymopapain (I)

versus microdiscectomy (C)

Österman [50], Finland

$(n=56)$

Sciatica for 6-12 weeks.

Microdiscectomy and physiotherapy

including isometric exercises (I) versus

information and physiotherapy

including isometric exercises (C)

Righesso [56], Brazil ( $n=40$ ) Macrodiscectomy (I) vs. microdiscectomy $(\mathrm{C})$

Peul [53, 54], Netherlands $(n=283)$

Sciatica for 6-12 weeks. Decompression of the nerve root by annular fenestration, curettage, and removal of loose degenerative disc material (I) versus home prolonged physiotherapy using a standardized exercise protocol (C)
}

Spinal stenosis and neurogenic claudication

Bezer [6], Turkey $(n=117) \quad$ Patients with unspecified degenerative disorder. All had decompression and posterior instrumentation. Bone grafting from same (I) or separate incision $(\mathrm{C})$

Thome [60], Germany

$(n=120)$

Bilateral (I) versus unilateral laminotomy (I2) versus laminectomy (C)

Korovessis [35], Greece $(n=135)$

Malmivaara [42], Finland $(n=94)$

Weinstein [69], USA

$(n=289)$

Hallett [23], Scotland $(n=44)$

Cavusoglu [9], Turkey $(n=100)$

Cho [13], China $(n=70)$

Dai [14], China $(n=62)$
Rigid (I) versus semirigid (I2) versus Dynamic (C) instrumentation, all had decompression

Decompressive surgery (I) versus nonoperative treatment (information and activation) (C)

Decompressive surgery (I) versus nonoperative treatment (information and activation) (C)

Patients with one-level root stenosis and degeneration. Instrumented posterolateral fusion (I) versus istrumented posterolateral fusion+ transforaminal interbody fusion (I2) vs no fusion (C). All had decompression

Patients had operation at 2-4 levels. Unilateral laminotomy (I) or laminectomy (C)

Split spinous process laminotomy (I) or discectomy (C)

Single level instrumented fusion with TCP (I) or autograft (C)
Pain, disability, complication, and reoperation: $\mathrm{I}=\mathrm{C}$

Leg and back pain at 1 and 2 years: $\mathrm{I}=\mathrm{C}$. Recurrence rate and satisfaction: $\mathrm{I}>\mathrm{C}$

Leg pain and satisfaction at 6 weeks, 6 months and 2 years: $\mathrm{I}>\mathrm{C}$. At 3 months and 1 year: $\mathrm{I}=\mathrm{C}$. Crossover $39 \%$. I > C

Pain, disability, and return to work over 2 No, no, no, no years: $\mathrm{I}=\mathrm{C}$

Relief of leg pain and perceived recovery Yes, yes, yes, yes up to 6 months: I > C. Cross-over $39 \%$

Complication, pain at donor site, overall Yes, no, no, no satisfaction: $\mathrm{I}>\mathrm{C}$

Pain: $\mathrm{I}>\mathrm{C}$, leg pain: $\mathrm{I}>\mathrm{I} 2=\mathrm{C}$, satisfaction; I $>\mathrm{I} 2=\mathrm{C}$, stability, walking distance: $\mathrm{I}=\mathrm{I} 2=\mathrm{C}$

Quality of life, back and leg pain and fusion rate: $\mathrm{I}=\mathrm{I} 2=\mathrm{C}$

Disability, back and leg pain at 1 and 2 Yes, yes, yes, yes years: I > C. Walking ability, selfreported and measured: $\mathrm{I}=\mathrm{C}$. Crossover $10 \%$, withdrawals from surgery $9 \%$

Disability: $\mathrm{I}=\mathrm{C}$, pain: $\mathrm{I}>\mathrm{C}$. Cross-over Yes, yes, yes, yes $43 \%$, withdrawals from surgery $33 \%$

Disability, pain, and quality of life: $\mathrm{I}=\mathrm{I} 2=\mathrm{C}$. Net costs were 43 and $68 \%$ higher for fusions: $\mathrm{C}>\mathrm{I}>\mathrm{I} 2$

Yes, yes, yes, yes

Disability, quality of life, pain or complications: $\mathrm{I}=\mathrm{C}$

Recovery rate: $\mathrm{I}>\mathrm{C}$, other factors: changes not statistically compared

Yes, no, no, no

No, no, no, no

Disability, quality of life and fusion rate: No, no, - , no $\mathrm{I}=\mathrm{C}$. More pain at donor site 
Table 2 continued

\begin{tabular}{|c|c|c|c|}
\hline Study & Patients and intervention & Treatment effect & $\begin{array}{l}\text { Quality rating } \\
\text { (concealed allocation, } \\
\text { flow chart, intention } \\
\text { to treat, } 95 \% \mathrm{CI} \text { ) }\end{array}$ \\
\hline
\end{tabular}

Spinal stenosis and neurogenic claudication and degenerative spondylolisthesis

Inamdar [27], India $(n=20) \quad$ Heterogenous group of patients. Posterior Disability, reduction of slip, fusion rate: No, no, no, no instrumentation (I) versus posterior $\quad \mathrm{I}=\mathrm{C}$. More complications in I interbody fusion (C). All patients had decompression

Weinstein [68], USA

$(n=304)$

Fernandez-Fairen [17], Spain $(n=82)$

CLBP and disc degeneration

Fairbank [15], UK $(n=349)$

Korovessis [36], Greece $(n=57)$

McKenna [43], UK $(n=83)$

Kim [31], South-Korea $(n=184)$

Sasso [58], USA $(n=67)$

Thoracolumbar burst fractures

Wood [72], USA $(n=43)$ instrumentation $(\mathrm{C})$

Wang [64], China $(n=48)$

Korovessis [34], Greece $(n=47)$

Spinal infections, metastasis, and miscellaneous

Ingham [28], England $(n=662)$

Young [74], USA

Albert [2], USA $(n=57)$ treatment $(\mathrm{C})$

Unilateral (I) versus bilateral instrumented fusion $(\mathrm{C})$ with instrumented fusion combined $(\mathrm{C} 2)$ circumferential fusion no bone graft $(\mathrm{C})$ versus penicillin $(\mathrm{C})$ radiotherapy $(\mathrm{C})$
Anterior (I) versus posterior

Decompressive laminectomy with or without fusion (I) versus non-operative

Lumbar spine fusion (I) or an intensive rehabilitation program based on cognitive behavioural therapy $(\mathrm{C})$

Coralline hydroxyapatite ( $\mathrm{CH}$ graules) (I) bone graft $(\mathrm{C})$ or both $(\mathrm{C} 2)$ in patients

Pain and disability $\mathrm{I}=\mathrm{C}$. Cross over $40 \%$, withdrawals from surgery $40 \%$. Analysis according to treatment received favoured surgery

Fusion rate and quality of life: $\mathrm{I}=\mathrm{C}$. Yes, no, no, no Reoperation rate: $\mathrm{I}>\mathrm{C}$

Disability, pain, quality of life: $\mathrm{I}=\mathrm{C} . \quad$ Yes, yes, yes, yes Cross-over $28 \%$

Disability, quality of life, back pain, fusion rate: $\mathrm{I}=\mathrm{C} 1=\mathrm{C} 2$. $\mathrm{CH}$-granules absorbed

Femoral ring allograft (I) versus titanium cage for circumferential fusion (C)

Heterogeneous population: degeneration, spondylo-listhesis, or stenosis. Posterolateral (I) versus posterior lumbar interbody fusion $(\mathrm{C} 1)$ versus

Metal-on-metal disc prosthesis versus

Disability and back pain not statistically No, no, no, no compared between groups. No difference for complication and reoperation. $\mathrm{I}=\mathrm{C}$

Hospitalization, pain, disability, quality of No, no, no, no life, return to work, kyphotic angle: $\mathrm{I}=\mathrm{C}$. More complications in $\mathrm{C}$

Instrumentation in with bone graft (I), or Kyphotic angle, low back pain: $\mathrm{I}=\mathrm{C}$

Combined anterior and posterior (I) versus short segment posterior (C)

Prophylactic antibiotics in neurosurgery, Infection rate: $\mathrm{I}=\mathrm{C}$ mostly laminectomy with or without fusion. Penicillin and sulphonamide (I)

Patients with spinal cord compression caused by metastatic cancer

Pain, walking ability: $\mathrm{I}=\mathrm{C}$ laminectomy + radiotherapy (I) vs.

Early (I) versus late blood autotransfusion Haemoglobin, reticulocyte count, (C)
No, no, no, no

Radiological and clinical parameters not No, no, no, no statistically compared

No, no, no, no mobilization: I $>$ C. Satisfaction, discomfort, stay at hospital: $\mathrm{I}=\mathrm{C}$ 
Table 2 continued

\begin{tabular}{|c|c|c|c|}
\hline Study & Patients and intervention & Treatment effect & $\begin{array}{l}\text { Quality rating } \\
\text { (concealed allocation, } \\
\text { flow chart, intention } \\
\text { to treat, } 95 \% \mathrm{CI} \text { ) }\end{array}$ \\
\hline $\begin{array}{l}\text { Rubinstein [57], Israel } \\
\quad n=166)\end{array}$ & $\begin{array}{l}\text { Patients undergoing surgery for CLBP } \\
\text { and disc degeneration and spinal } \\
\text { stenosis. Profylactic antibiotics } \\
\text { (cephazolin) (I) versus placebo (C) }\end{array}$ & $\begin{array}{l}\text { Postoperative infections (for wound } \\
\text { infection } P=0.07 \text { ) and hospital stay: } \\
\text { I }>\text { C }\end{array}$ & $\begin{array}{l}\text { Yes, no, no, no } \\
\quad \text { (double-blind) }\end{array}$ \\
\hline Laine [37], Finland $(n=100)$ & $\begin{array}{l}\text { Computer-assisted (optoelectronic } \\
\text { navigation system) (I) versus } \\
\text { conventional pedicle screw placement } \\
\text { (C) }\end{array}$ & $\begin{array}{l}\text { Pedicle perforation rate and size of } \\
\text { perforations: } \mathrm{I}>\mathrm{C}\end{array}$ & No, no, no, no \\
\hline $\begin{array}{l}\text { Cheng [12], Taiwan (China) } \\
(n=417)\end{array}$ & $\begin{array}{l}\text { Antiseptic and bactericidal wound } \\
\text { irrigation }(5 \mathrm{ml} \text { with } 3.5 \% \text { betadin) (I) } \\
\text { versus none (C). Both groups had } \\
\text { antibiotics i.v. for } 2 \text { days and orally for } \\
3 \text { days }\end{array}$ & $\begin{array}{l}\text { Deep and total postoperative infection } \\
\text { rate: } \mathrm{I}>\mathrm{C}\end{array}$ & No, no,,- no \\
\hline Patchell [52], USA $(n=123)$ & $\begin{array}{l}\text { Patients with spinal cord compression } \\
\text { caused by metastatic cancer. } \\
\text { Surgery }+ \text { radiotherapy (I) versus } \\
\text { radiotherapy (C) }\end{array}$ & $\begin{array}{l}\text { Walking ability, need for medication: } \\
\quad \mathrm{I}>\mathrm{C}\end{array}$ & No, yes, yes, yes \\
\hline $\begin{array}{l}\text { Nakamura [49], Japan } \\
\quad(n=39)\end{array}$ & $\begin{array}{l}\text { Patients with dural lesion. Autologous } \\
\text { fibrin tissue adhesive (I) versus, dura } \\
\text { closure (C1) versus use of commercial } \\
\text { fibrin (C2) }\end{array}$ & $\begin{array}{l}\text { Drainage fluid: } \mathrm{I}=\mathrm{C} 2>\mathrm{C} 1 \text {. Costs } \\
\text { higher for commercial fibrin }\end{array}$ & No, no, - , no \\
\hline $\begin{array}{l}\text { Çelik and Kara [10], Turkey } \\
(n=789)\end{array}$ & $\begin{array}{l}\text { Unshaved skin (I) versus shaved } \\
\text { preoperatively (C) }\end{array}$ & Postoperative infections: $\mathrm{I}>\mathrm{C}$ & No, no, no, no \\
\hline $\begin{array}{l}\text { Linhardt [40], Germany } \\
\quad(n=22)\end{array}$ & $\begin{array}{l}\text { Patients with infectious spondylitis. } \\
\text { Ventral instrumented spondylodesis (I) } \\
\text { versus ventrodorsal instrumented } \\
\text { spondylodesis (C) }\end{array}$ & $\begin{array}{l}\text { Results in favour of ventral, but statistical } \\
\text { comparison for the difference in change } \\
\text { between groups not provided }\end{array}$ & Yes, no, no, no \\
\hline
\end{tabular}

${ }^{a}$ Eight patients excluded in group I after randomization and allocation by birth day (even or uneven)

- Reported no loss to follow-up

Other trials

Limited evidence is provided for early versus late blood transfusion [2], computer-assisted versus conventional screw placement [37], and autologous fibrin tissue adhesive [49].

\section{Discussion}

Like the tortoise, we should prepare ourselves for the challenges that lie ahead. We must not assume that simply because we believe in a new diagnostic technique or a new procedure, it is truly a desirable and safe method. After all, it was the tortoise who prepared for the race, took his time, and won, Dr. Weinstein wrote in an editorial in Spine in 1999 [66].

Figure 1 illustrates an increase in the number of RCTs in spinal surgery and the use of concealed allocation after 1999. These trials provide evidence that can improve the quality of spine surgery. Several questions remain unanswered, and a continuous increase in the number of trials along with improvement of their quality is warranted. Trials should follow the standards outlined in the CONSORT statement [47], and referees and editors should check manuscripts according to these standards.

The best documented procedure in spine surgery is discectomy in selected patients with disc prolapse and sciatica. Therefore, it is a paradox that I usually do not recommend surgery for these patients, and these include spine surgeons, colleagues, and friends. They usually do not prefer surgery, and most of them recover completely without. Critics of evidence-based medicine would argue that my clinical practice illustrates that there is no place for evidence-based medicine. On the contrary, I am very confident that there is strong evidence to recommend discectomy for patients who cannot stand their leg pain.

This updated review including recently published highquality trials [42, 69] provide moderate evidence that surgery is more effective than conservative treatment for pain relief in patients with spinal stenosis. Surgery might not improve walking distance [42], which might be due to 
comorbid conditions in the elderly population. None of the trials report better results after instrumentation, and even in patients with concomitant degenerative spondylolisthesis, this is a controversy. Considering the increased risk for infections and complications, particularly in elderly patients, the recommendation for instrumentation should, according to evidence-based medicine, be limited to RCTs.

One recent systematic review and one meta-analysis on fusion in patients with CLBP and disc degeneration concluded that this procedure is not more effective than modern rehabilitation based on cognitive behavioural principles [26, 46]. Meanwhile, spine surgeons have focused more on hypothesized adjacent level disc degeneration after fusion and the advantages of disc prostheses. Considering the most likely placebo effects of introducing a new device, the trials published comparing disc prosthesis with fusion are not convincing for the recommendation of disc prosthesis in carefully selected patients with CLBP.

One trial published on patients with thoracolumbar burst fractures without neurological compromise suggests that surgery is not better than conservative treatment. The trial was small and further trials are warranted. Ongoing trials with protocols on http://www.clinicaltrials.gov/ evaluate the effectiveness of vertebro- and kyphoplasty in osteoporotic fractures, but only one published trial with 2 weeks follow-up was identified until July 2008. One of the registered trials compares vertebroplasty with sham surgery.

The latest Cochrane Review on spinal tuberculosis concludes that routine surgery can be recommended only in the context of a large, well-documented controlled trial. Considering the burden of this disease, the international spine society should stimulate further studies in this field.

Several studies have examined the effectiveness of prophylactic interventions to prevent infections. Because infections are relatively low, some of these studies may be underpowered and multicentre trials or register data may be more appropriate to evaluate the type and administration of antibiotics.

The aim of this article was to describe the contribution of RCTs to quality management and their feasibility in practice, and not to conduct a systematic review. To give an overview, the conclusions of the latest Cochrane Reviews are presented along with results from an updated search. All published RCTs in this field have not been identified, by example the search was limited to Medline and trials published in English. In addition, two authors did not evaluate the identified trials independently. Despite possible selection and observer bias, the major results are in agreement with the latest Cochrane Reviews and later published systematic reviews [19, 20, 26, 46].
The idea of presenting trials from fields in spine surgery that has not been evaluated in a Cochrane Review was to give an overview, excluding neck surgery, and to possibly stimulate spine surgeons to conduct a systematic review, by example on interventions to prevent postoperative infections.

Another challenge is the implementation of the evidence provided. Surgeons will always focus on new techniques based on information obtained in the laboratory, but new procedures should be marketed only after clinical trials. The story from the1970s, the large-scale clinical failure of the Christiansen hip prosthesis [24] and Boneloc cement [39] demonstrate the unforeseen consequences of not performing a randomized trial. Like the hare, we are at risk of being over-confident. Spine surgeons focus on instrumentation because they strongly believe that it provide the best method to stabilize the segments. This in turn is important for treatment success in CLBP and spondylolisthesis and to prevent treatment failure in older patients having decompression for spinal stenosis. Not surprising according to this view, a recent article challenges the assertion that spine surgeons have undue financial incentive to recommend combined decompression and instrumented fusion to patients with symptomatic lumbar degeneration [71]. Beliefs in the effectiveness of stabilization may explain why rates of fusion and the use of instrumentation seem to have increased independently of the limited scientific evidence available [67]. The increased use of advanced imaging may also have contributed to surgery rates [41]. The gap between the increased use of instrumentation and the results provided by evidence-based medicine emphasize the importance of encouraging spine surgeons to read and understand the advantage of RCTs to provide the best evidence.

\section{External validity of RCTs}

Many spine surgeons find it difficult to put the RCTs in context of the clinical needs and realities which may reduce the external validity of RCTs and hamper the implementation of treatment strategies from evidencebased medicine. By example, patients may not be representative because selection criteria are inappropriate, the experience and skill of the surgeon are difficult to standardize, and the principle of intention to treat is difficult to understand. If back surgeons do not find the evidence from RCTs helpful, it will be difficult to improve the level of evidence from "in my experience".

It is easy to forget that bias and confounding always play an important role for "in my experience", and that RCTs are designed in order to reduce these factors. The spine surgeon may argue that if the patient is really suffering and 
in a free healthcare environment, she wants to know what is best for her. That is what evidence-based medicine is about; to give the patient the best treatment available or to inform about the alternatives, the risks, and the prognosis with or without surgery. The spine surgeon himself would most likely prefer to have evidence-based treatment for back pain - and if surgery is the best choice he would prefer to select the surgeon.

RCTs are not only helpful just to compare two devices, but also to study the effectiveness of spine surgery per se. Certain surgical treatments, such as vertebroplasty for osteoporotic fractures, provide the option of being compared with sham surgery. The results from the first RCT designed to compare sham surgery and spine surgery are expected to be widely discussed among researchers and clinicians (http://www.clinicaltrials.gov/). If the surgical technique applied is no better than sham surgery it may not be ethical to provide surgery.

Considering all the limitations, the knowledge gained from studies with a proper scientific design is considered to be far more reliable than the clinical experience of an individual surgeon. The aim is to combine evidence-based medicine and clinical skills in order to provide the best or most cost-effective treatment for the individual patient in an unbiased healthcare environment.

Feasibility in practice

\section{When are randomized trials unnecessary?}

Some treatments have dramatic effects that are highly unlikely to reflect inadequately controlled biases. Historical examples are blood transfusion for severe haemorrhagic shock; closed reduction and splinting for fracture of long bones with displacement; suturing for repairing large wounds; and drainage for pain associated with abscesses.

A unifying principle is the size of the treatment effect (signal) relative to the expected prognosis (noise) of the condition. In a recent publication the authors considered that when the rate exceeds 10 it is highly unlikely to reflect bias or other factors than a treatment effect [21]. Examples from spine surgery are the cauda equina syndrome, spinal tumours, and the reduction of the major curve in adolescent idiopathic scoliosis. Also patients with burst fractures and neurological compromise are considered to be included in this category.

\section{When are RCTs difficult to conduct?}

Spine surgeons and patients agree in that the skills of the surgeon are important for results. Also authorities of clinical trials consider the skills of the surgeon an important issue. Nevertheless, this issue has not been assessed in RCTs, reflecting the problems considered to conduct such a study.

\section{Is the RCT feasible?}

First, the aim of the study should be clearly defined, and then a systematic search in medical databases and registers for clinical trials, systematic reviews, and metaanalyses should be made. A randomized clinical trial is a resourcedemanding project for several years.

\section{Are the selected group of patients available?}

In the planning of a trial most clinicians believe that availability of patients is not a problem, not facing the law of Laplace until a few months or even a year have relapsed and either the pool from which the patients should be selected is too small, or most are excluded. To avoid this problem, researchers may ask other hospitals to send patients or to collaborate in a multi-centre study, or decide that the trial is not possible to conduct.

\section{What are the preferred outcome measures?}

Validated questionnaires to evaluate pain and disability are recommended in any clinical trial on spine surgery. In addition, questions about sickness absence, patient satisfaction and a global score to evaluate improvement are advisable. Other measures (by example radiological, physical or costs) should be obtained according to the main hypothesis of the trial. The choice of outcome measures should be decided upon in advance and primary and secondary outcome measures should be described in the protocol.

\section{What is the CONSORT statement?}

The revised CONSORT statement includes a 22-item checklist (Table 3) and a flow chart [47]. Its main aim is to help authors to improve the quality of RCTs and to aid peer reviewers and editors to identify the reports of inadequate description and potentially biased results. Table 2 demonstrates that reporting on concealed allocation, the use of flow chart, intention to treat analysis, and difference in change between treatments with $95 \%$ confidence interval, were not properly reported in the majority of trials. RCTs may not be feasible if authors do not adhere to the CONSORT statement. For publication also registration of the protocol is required by most journals. Use of the $\mathrm{CON}$ SORT check list is also of great value in writing up a RCT. 
Table 3 Checklist of items to include when reporting a randomised trial (CONSORT statement, published with permission from Lancet)

\begin{tabular}{|c|c|c|c|}
\hline & Item number & Descriptor & $\begin{array}{l}\text { Reported on } \\
\text { page number }\end{array}$ \\
\hline Title and abstract & 1 & $\begin{array}{l}\text { How participants were allocated to interventions (e.g. "random } \\
\text { allocation", "randomized", or "randomly assigned") }\end{array}$ & \\
\hline \multicolumn{4}{|l|}{ Introduction } \\
\hline Background & 2 & Scientified background and explanation of rationale & \\
\hline \multicolumn{4}{|l|}{ Methods } \\
\hline Participants & 3 & $\begin{array}{l}\text { Eligibillity criteria for participants and the settings and locations } \\
\text { where the data were collected }\end{array}$ & \\
\hline Interventions & 4 & $\begin{array}{l}\text { Precise details of the interventions intended for each group and } \\
\text { how and when they were actually administered }\end{array}$ & \\
\hline Objectives & 5 & Specific objectives and hypotheses & \\
\hline Outcomes & 6 & $\begin{array}{l}\text { Clearly defined primary and secondary outcome measures and, } \\
\text { when applicable, any methods used to enhance the quality of } \\
\text { measurements (e.g. multiple observations, training of assessors, } \\
\text { \&c) }\end{array}$ & \\
\hline Sample size & 7 & $\begin{array}{l}\text { How sample size was determined and, when applicable, } \\
\text { explanation of any interim analyses and stopping rules }\end{array}$ & \\
\hline \multicolumn{4}{|l|}{ Randomization } \\
\hline Sequence generation & 8 & $\begin{array}{l}\text { Method used to generate the random allocation sequence, } \\
\text { including details of any restriction (e.g. blocking, stratification) }\end{array}$ & \\
\hline Allocation concealment & 9 & $\begin{array}{l}\text { Method used to implement the random allocation sequence (e.g. } \\
\text { numbered containers or central telephone), clarifying whether } \\
\text { the sequence was concealed until interventions were assigned }\end{array}$ & \\
\hline Implementation & 10 & $\begin{array}{l}\text { Who generated the allocation sequence, who enroled participants, } \\
\text { and who assigned participants to their groups }\end{array}$ & \\
\hline Blinding (masking) & 11 & $\begin{array}{l}\text { Whether or not participants, those administering the interventions, } \\
\text { and those assessing the outcomes were aware of group } \\
\text { assignment. If not, how the success of masking was assessed }\end{array}$ & \\
\hline Statistical methods & 12 & $\begin{array}{l}\text { Statistical methods used to compare groups for primary } \\
\text { outcome(s); methods for additional analyses, such as subgroup } \\
\text { analyses and adjusted analyses }\end{array}$ & \\
\hline \multicolumn{4}{|l|}{ Results } \\
\hline Participant flow & 13 & $\begin{array}{l}\text { Flow of participants through each stage (a diagram is strongly } \\
\text { recommended), Specifically, for each group, report the numbers } \\
\text { of participants randomly assigned, receiving intended treatment, } \\
\text { completing the study protocol, and analysed for the primary } \\
\text { outcome. Describe protocol deviations from study as planned, } \\
\text { together with reasons }\end{array}$ & \\
\hline Recruitment & 14 & Dates defining the periods of recruitment and follow-up & \\
\hline Baseline data & 15 & Baseline demographic and clinical characteristics of each group & \\
\hline Numbers analysed & 16 & $\begin{array}{l}\text { Number of participants (denominator) in each group included in } \\
\text { each analysis and whether the analysis was by "intention to } \\
\text { treat". State the results in absolute numbers when feasible (e.g. } \\
10 / 20 \text {, not } 50 \% \text { ) }\end{array}$ & \\
\hline Outcomes and estimation & 17 & $\begin{array}{l}\text { For each primary and secondary outcome, a summary of results for } \\
\text { each group, and the estimated effect size and its precision (e.g. } \\
95 \% \mathrm{Cl} \text { ) }\end{array}$ & \\
\hline Ancillary analyses & 18 & $\begin{array}{l}\text { Address multiplicity by reporting any other analyses performed, } \\
\text { including subgroup analyses and adjusted analyses, indicating } \\
\text { those prespecified and those exploratory }\end{array}$ & \\
\hline Adverse events & 19 & $\begin{array}{l}\text { All important adverse events or side-effects in each intervention } \\
\text { group }\end{array}$ & \\
\hline
\end{tabular}


Table 3 continued

\begin{tabular}{lll}
\hline $\begin{array}{l}\text { Item number } \\
\text { Interpretation }\end{array}$ & Descriptor & $\begin{array}{c}\text { Reported on } \\
\text { page number }\end{array}$ \\
$\begin{array}{l}\text { Generalizability } \\
\text { Overall evidence }\end{array}$ & 21 & $\begin{array}{c}\text { Interpretation of the results, taking into account study hypothesses, } \\
\text { sources of potential bias or imprecision and the dangers } \\
\text { associated with multiplicity of analyses and outcomes } \\
\text { Generalisability (external validity) of the trial findings } \\
\text { General interpretation of the results in the context of current } \\
\text { evidence }\end{array}$ \\
\hline
\end{tabular}

\section{Conclusion}

The RCTs are increasingly applied to improve the quality of spine surgery. At the same time new methods that have not been evaluated by RCTs are introduced for the treatment of spinal disorders. While recent RCTs document the faster relief for old surgical methods such as discectomy for the treatment of lumbar disc herniation in patients with sciatica and suggest reduced pain after decompression in spinal stenosis, the evidence for more sophisticated methods are conflicting or limited. Implementation of new methods should be based on sound evidence. This is important for the reputation of spine surgery and for the patient complaining from a spinal disorder in the hands of a spine surgeon.

Acknowledgments The author thanks the spine surgeons Jeremy Fairbank and Christian Hellum, neurosurgeon Øystein P. Nygaard, and professor Olav Reikerås for comments on the draft of this article.

Conflict of interest statement None of the authors has any potential conflict of interest.

Open Access This article is distributed under the terms of the Creative Commons Attribution Noncommercial License which permits any noncommercial use, distribution, and reproduction in any medium, provided the original author(s) and source are credited.

\section{References}

1. Airaksinen O, Brox JI, Cedraschi C, Hildebrandt J, KlaberMoffett J, Kovacs F, Mannion AF, Reis S, Staal JB, Ursin H, Zanoli G (2006) European guidelines for the management of chronic nonspecific low back pain. Eur Spine J Suppl 2:S192S300. doi:10.1007/s00586-006-1072-1

2. Albert TJ, Desai D, McIntosh T, Lamb D, Balderston RA (1993) Early versus late replacement of autotransfused blood in elective spinal surgery. A prospective randomized study. Spine 18:10711078

3. Amundsen T, Weber H, Nordal HJ, Magnæs B, Abdelnoor M, Lilleås $\mathrm{F}$ (2000) Lumbar spinal stenosis: conservative or surgical management? A prospective 10-year study. Spine 25:1424-1435. doi:10.1097/00007632-200006010-00016
4. Anderson PA, Tribus CB, Kitchel SH (2006) Treatment of neurogenic claud-ication by interspinous decompression: application of the X STOP device in patients with lumbar degenerative spondylolisthesis. J Neurosurg Spine 4:463-471. doi:10.3171/ spi.2006.4.6.463

5. Baron JH (1998) Never underestimate a placebo. BMJ 317:1190

6. Bezer M, Erol B, Kocaoğlu B, Aydin N, Güven O (2004) Comparison of traditional and intrafascial iliac crest bone-graft harvesting in lumbar spinal surgery. Int Orthop 28:325-328. doi: 10.1007/s00264-004-0594-6

7. Brox JI, Sørensen R, Friis A, Nygaard Ø, Indahl A, Keller A, Ingbrigtsen T, Eriksen HR, Holm I, Rise R, Koller AK, Reikerås $\mathrm{O}$ (2003) Randomized clinical trial of lumbar instrumented fusion and cognitive intervention and exercises in patients with chronic low back pain and disc degeneration. Spine 28:1913-1921. doi: 10.1097/01.BRS.0000083234.62751.7A

8. Brox JI, Reikerås O, Nygaard Ø, Sørensen R, Indahl A, Holm I, Keller A, Ingebrigtsen T, Grundnes O, Lange JE, Friis A (2006) Lumbar instrumented fusion compared with cognitive intervention and exercises in patients with chronic back pain after previous surgery for disc herniation: a prospective randomized controlled study. Pain 122:145-155. doi:10.1016/j.pain.2006.01. 027

9. Cavusoglu H, Turkmenoglu O, Kaya RA, Tuncer C, Colak I, Sahin Y, Aydin Y (2007) Efficacy of unilateral laminectomy for bilateral decompression in lumbar spinal stenosis. Turk Neurosurg 17:100-108

10. Celik SE, Kara A (2007) Does shaving the incision site increase the infection rate after spinal surgery? Spine 32:1575-1577. doi: 10.1097/BRS.0b013e318074c39f

11. Chalmers TC (1972) Randomization and coronary artery surgery. Ann Thorac Surg 14:323-327

12. Cheng MT, Chang MC, Wang ST, Yu WK, Liu CL, Chen TH (2005) Efficacy of dilute betadine solution irrigation in the prevention of postoperative infection of spinal surgery. Spine 30:1689-1693. doi:10.1097/01.brs.0000171907.60775.85

13. Cho DY, Lin HL, Lee WY, Lee HC (2007) Split-spinous process laminotomy and discectomy for degenerative lumbar spinal stenosis: a preliminary report. J Neurosurg Spine 6:229-239. doi: 10.3171/spi.2007.6.3.229

14. Dai LY, Jiang LS (2008) Single-level instrumented posterolateral fusion of lumbar spine with beta-tricalcium phosphate versus autograft: a prospective, randomized study with 3-year follow-up. Spine 33:1299-1304. doi:10.1097/BRS.0b013e3181732a8e

15. Fairbank J, Frost H, Wilson-MacDonald J, Yu LM, Barker K, Collins R (2005) Randomised controlled trial to compare surgical stabilisation of the lumbar spine with an intensive rehabilitation programme for patients with chronic low back pain: the MRC spine stabilisation trial. BMJ 303:1233-1239. doi:10.1136/bmj. 38441.620417.8F 
16. Fei Q, Wang YP, Xu HG, Qiu GX, Weng XS, Lin J, Tian Y, Yu B, Xu R (2005) Comparison of instrumented posterior fusion with instrumented circumferential lumbar fusion in the treatment of lumbar stenosis with low degree lumbar spondylolisthesis. Zhonghua Wai Ke Za Zhi 43:486-490

17. Fernandez-Fairen M, Sala P, Ramirez H, Gil J (2007) A prospective randomized study of unilateral versus bilateral instrumented posterolateral lumbar fusion in degenerative spondylolisthesis. Spine 32:395-401. doi:10.1097/01.brs.0000255023.56466.44

18. Fields WS, Maslenikov V, Meyer JS, Hass WK, Remington RD, Macdonald M (1970) Joint study of extracranial arterial occlusion. V. Progress report of prognosis following surgery or nonsurgical treatment for transient cerebral ischemic attacks and cervical carotid artery lesions. JAMA 1211:1993-2003. doi: 10.1001/jama.211.12.1993

19. Gibson JN, Waddell G (2005) Surgery for degenerative lumbar spondylosis. Cochrane Database Syst Rev CD001352

20. Gibson JN, Waddell G (2007) Surgical interventions for lumbar disc prolapse: updated Cochrane Review. Spine 32:1735-1747. doi:10.1097/BRS.0b013e3180bc2431

21. Glasziou P, Chalmers I, Rawlins M, McCulloch P (2007) When are randomised trials unnecessary? Picking signal from noise. BMJ 334:349-351. doi:10.1136/bmj.39070.527986.68

22. Goupille P, Mulleman D, Mammou S, Griffoul I, Valat JP (2007) Percutaneous laser disc decompression for the treatment of lumbar disc herniation: a review. Semin Arthritis Rheum 1:2030. doi:10.1016/j.semarthrit.2007.01.006

23. Hallett A, Huntley JS, Gibson JN (2007) Foraminal stenosis and single-level degenerative disc disease: a randomized controlled trial comparing decompression with decompression and instrumented fusion. Spine 32:1375-1380. doi:10.1097/BRS. 0b013e318064520f

24. Havelin LI, Espehaug B, Vollset SE, Engesæter LB (1995) The effect of the type of cement on early revision of Charnley total hip prostheses. A review of eight thousand five hundred and seventy-nine primary arthroplasties from the Norwegian Arthroplasty Register. J Bone Joint Surg Am 77:1543-1550

25. Hoogland T, Schubert M, Miklitz B, Ramirez A (2006) Transforaminal postero-lateral endoscopic discectomy with or without the combination of a low-dose chymopapain: a prospective randomized study in 280 consecutive cases. Spine 31:E890-E897. doi:10.1097/01.brs.0000245955.22358.3a

26. Ibrahim T, Tleyjeh IM, Gabbar O (2008) Surgical versus nonsurgical treatment of chronic low back pain: a meta-analysis of randomised trials. Int Orthop 32:107-113. doi:10.1007/s00264006-0269-6

27. Inamdar DN, Alagappan M, Shyam L, Devadoss S, Devadoss A (2006) Posterior lumbar interbody fusion versus intertransverse fusion in the treatment of lumbar spondylolisthesis. J Orthop Surg (Hong Kong) 14:21-26

28. Ingham HR, Kalbag RM, Sisson PR, Allcutt DA, Betty MJ, Crawford PJ, Gillham NR, Hankinson J, Sengupta RP, Strong AJ (1988) Simple peroperative antimicrobial chemoprophylaxis in elective neurosurgical operations. J Hosp Infect 12:225-233. doi: 10.1016/0195-6701(88)90011-4

29. Jutte PC, Van Loenhout-Rooyackers JH (2006) Routine surgery in addition to chemotherapy for treating spinal tuberculosis. Cochrane Database Syst Rev CD004532

30. Katayama Y, Matsuyama Y, Yoshihara H, Sakai Y, Nakamura H, Nakashima S, Ito Z, Ishiguro N (2006) Comparison of surgical outcomes between macro discectomy and micro discectomy for lumbar disc herniation: a prospective randomized study with surgery performed by the same spine surgeon. J Spinal Disord Tech 19:344-347. doi:10.1097/01.bsd.0000211201.93125.1c

31. Kim KT, Lee SH, Lee YH, Bae SC, Suk KS (2006) Clinical outcomes of 3 fusion methods through the posterior approach in the lumbar spine. Spine 31:1351-1357. doi:10.1097/01.brs. 0000218635.14571 .55

32. Kondrashov DG, Hannibal M, Hsu KY, Zucherman JF (2006) Interspinous process decompression with the X-STOP device for lumbar spinal stenosis: a 4-year follow-up study. J Spinal Disord Tech 19:323-327. doi:10.1097/01.bsd.0000211294.67508.3b

33. Kornblum MB, Fischgrund JS, Herkowitz HN, Abraham DA, Berkower DL, Ditkoff JS (2004) Degenerative lumbar spondylolisthesis with spinal stenosis-a prospective long-term study comparing fusion and pseudarthrosis. Spine 29:726-733. doi: 10.1097/01.BRS.0000119398.22620.92

34. Korovessis P, Baikousis A, Koureas G, Zacharatos S (2004) Correlative analysis of the results of surgical treatment of thoracolumbar injuries with long Texas Scottish rite hospital construct: is the use of pedicle screws versus hooks advantageous in the lumbar spine? J Spinal Disord Tech 17:195-205. doi: 10.1097/00024720-200406000-00006

35. Korovessis P, Papazisis Z, Koureas G, Lambiris E (2004) Rigid, semirigid versus dynamic instrumentation for degenerative lumbar spinal stenosis: a corr-elative radiological and clinical analysis of short-term results. Spine 29:735-742. doi:10.1097/ 01.BRS.0000112072.83196.0F

36. Korovessis P, Repanti M, Koureas G (2002) Does coralline hydroxyapatite conduct fusion in instrumented posterior spine fusion? Stud Health Technol Inform 91:109-113

37. Laine T, Lund T, Ylikoski M, Lohikoski J, Schlenzka D (2000) Accuracy of pedicle screw insertion with and without computer assistance: a randomised controlled clinical study in 100 consecutive patients. Eur Spine J 9:235-240. doi:10.1007/s005860000146

38. Lind J (1753) A treatise of scurvy. Sands Murray \& Cochran, Edinburgh

39. Linder L (1995) Boneloc: the Christiansen experience revisited. Acta Orthop Scand 66:205-206

40. Linhardt O, Matussek J, Refior HJ, Krodel A (2007) Long-term results of ventro-dorsal versus ventral instrumentation fusion in the treatment of spondylitis. Int Orthop 31:113-119. doi:10.1007/ s00264-006-0140-9

41. Lurie JD, Birkmeyer NJ, Weinstein JN (2003) Rates of advanced spinal imaging and spine surgery. Spine 28:616-620. doi: 10.1097/00007632-200303150-00018

42. Malmivaara A, Slatis $P$, Heliovaara $M$, Sainio $P$, Kinnunen $H$, Kankare J, Hirvonen N, Seitsalo S, Herno A, Kortekangas P, Niinimaki T, Ronty H, Tallroth K, Turunen V, Knekt P, Harkanen T, Hurri H (2007) Surgical or nonoperative treatment for lumbar spinal stenosis? A randomized controlled trial. Spine 32:1-8. doi:10.1097/01.brs.0000251014.81875.6d

43. McKenna PJ, Freeman BJ, Mulholland RC, Grevitt MP, Webb JK, Mehdian SH (2005) A prospective, randomised controlled trial of femoral ring allograft versus a titanium cage in circumferential lumbar spinal fusion with minimum 2-year clinical results. Eur Spine J 14:727-737. doi:10.1007/s00586-005-1034-Z

44. Medical Research Council (1948) Streptomycin treatment of pulmonary tuberculosis. BMJ ii:425-429

45. Medical Research Council Working party on tuberculosis (1974) A controlled trial of anterior spinal fusion and debridement in the surgical management of tuberculosis of the spine in patients on standard chemotherapy: a study in Hong Kong. Br J Surg 61:853-866

46. Mirza SK, Deyo RA (2007) Systematic review of randomized trials comparing lumbar fusion surgery to nonoperative care for treatment of chronic back pain. Spine 32:816-823. doi:10.1097/ 01.brs.0000259225.37454.38

47. Moher D, Schulz KF, Altman DG (2001) The CONSORT statement: revised recommendations for improving the quality of reports of parallel-group randomised trials. Lancet 357:11911194. doi:10.1016/S0140-6736(00)04337-3 
48. Mussano F, Ciccone G, Ceccarelli M, Baldi I, Bassi F (2007) Bone morphogenetic proteins and bone defects: a systematic review. Spine 32:824-830. doi:10.1097/01.brs.0000259227. 51180.ca

49. Nakamura H, Matsuyama Y, Yoshihara H, Sakai Y, Katayama Y, Nakashima S, Takamatsu J, Ishiguro N (2005) The effect of autologous fibrin tissue adhesive on postoperative cerebrospinal fluid leak in spinal cord surgery: a randomized controlled trial. Spine 30:E347-E351. doi:10.1097/01.brs.0000167820.54413.8e

50. Österman H, Seitsalo S, Karppinen J, Malmivaara A (2006) Effectiveness of microdiscectomy for lumbar disc herniation: a randomized controlled trial with 2 years of follow-up. Spine 31:2409-2414. doi:10.1097/01.brs.0000239178.08796.52

51. Parker MJ, Livingstone V, Clifton R, McKee A (2007) Closed suction surgical wound drainage after orthopaedic surgery. Cochrane Database Syst Rev CD001825

52. Patchell RA, Tibbs PA, Regine WF, Payne R, Saris S, Kryscio RJ, Mohiuddin M, Young B (2005) Direct decompressive surgical resection in the treatment of spinal cord compression caused by metastatic cancer: a randomised trial. Lancet 366:643-648. doi:10.1016/S0140-6736(05)66954-1

53. Peul WC, van den Hout WB, Brand R, Thomeer RT, Koes BW (2008) Pro-longed conservative care versus early surgery in patients with sciatica caused by lumbar disc herniation: two year results of a randomised controlled trial. BMJ 336:1355-1358. doi:10.1136/bmj.a143

54. Peul WC, van Houwelingen HC, van den Hout WB, Brand R, Eekhof JA, Tans JT, Thomeer RT, Koes BW (2007) Surgery versus prolonged conservative treatment for sciatica. N Engl J Med 356:2245-2256. doi:10.1056/NEJMoa064039

55. Pocock SJ (1983) Clinical trials. Wiley, New York

56. Righesso O, Falavigna A, Avanzi O (2007) Comparison of open discectomy with microendoscopic discectomy in lumbar disc herniations: results of a randomized controlled trial. Neurosurgery 61:545-549. doi:10.1227/01.NEU.0000290901.00320.F5

57. Rubinstein E, Findler G, Amit P, Shaked I (1994) Perioperative prophylactic cephazolin in spinal surgery. A double-blind placebo-controlled trial. J Bone Joint Surg Br 76:99-102

58. Sasso RC, Smucker JD, Hacker RJ, Heller JG (2007) Artificial disc versus fusion: a prospective, randomized study with 2-year follow-up on 99 patients. Spine 32:2933-2940. doi:10.1097/ BRS.0b013e31815d0034

59. Schofferman J, Slosar P, Reynolds J, Goldthwaite N, Koestler M (2001) A prospective randomized comparison of 270 degrees fusions to 360 degrees fusions (circumferential fusions). Spine 26:E207-E212. doi:10.1097/00007632-200105150-00019

60. Thome C, Zevgaridis D, Leheta O, Bazner H, Pockler-Schoniger C, Wohrle J, Schmiedek P (2005) Outcome after less-invasive decompression of lumbar spinal stenosis: a randomized comparison of unilateral laminotomy, bilateral laminotomy, and laminectomy. J Neurosurg Spine 3:129-141

61. van den Hout WB, Peul WC, Koes BW, Brand R, Kievit J, Thomeer RT (2008) Prolonged conservative care versus early surgery in patients with sciatica from lumbar disc herniation: cost utility analysis alongside a randomised controlled trial. BMJ 336:1351-1354. doi:10.1136/bmj.39583.709074.BE

62. van Tulder MW, Koes B, Seitsalo S, Malmivaara A (2006) Outcome of invasive treatment modalities on back pain and sciatica: an evidence-based review. Eur Spine J 15:S82-S92

63. Voormolen MH, Mali WP, Lohle PN, Fransen H, Lampmann LE, van der Graaf Y, Juttmann JR, Jansssens X, Verhaar HJ (2007) Percutaneous vertebroplasty compared with optimal pain medication treatment: short-term clinical outcome of patients with subacute or chronic painful osteoporotic vertebral compression fractures. The VERTOS study. AJNR Am J Neuroradiol 28:555560

64. Wang ST, Ma HL, Liu CL, Yu WK, Chang MC, Chen TH (2006) Is fusion necessary for surgically treated burst fractures of the thoracolumbar and lumbar spine? A prospective, randomized study. Spine 31:2646-2652. doi:10.1097/01.brs.0000244555. 28310.40

65. Weber H (1983) Lumbar disc herniation A controlled, prospective study with ten years of observation. Spine 8:131-140. doi: 10.1097/00007632-198303000-00003

66. Weinstein JN (1999) The tortoise and the hare: is there a place in spine surgery for randomized trials? Spine 24:2548-2549. doi: 10.1097/00007632-199912010-00018

67. Weinstein JN, Lurie JD, Olson PR, Bronner KK, Fisher ES (2006) United States' trends and regional variations in lumbar spine surgery: 1992-2003. Spine 31:2707-2714

68. Weinstein JN, Lurie JD, Tosteson TD, Hanscom B, Tosteson AN, Blood EA, Birkmeyer NJ, Hilibrand AS, Herkowitz H, Cammisa FP, Albert TJ, Emery SE, Lenke LG, Abdu WA, Longley M, Errico TJ, Hu SS (2007) Surgical versus non-surgical treatment for lumbar degenerative spondylolisthesis. $\mathrm{N}$ Engl J Med 356:2257-2270. doi:10.1056/NEJMoa070302

69. Weinstein JN, Tosteson TD, Lurie JD, Tosteson AN, Blood E, Hanscom B, Herkowitz H, Cammisa F, Albert T, Boden SD, Hilibrand A, Goldberg H, Berven S, An H (2008) Surgical versus nonsurgical therapy for lumbar spinal stenosis. N Engl J Med 358:794-810. doi:10.1056/NEJMoa0707136

70. Weinstein JN, Tosteson TD, Lurie JD, Tosteson AN, Hanscom B, Skinner JS, Abdu WA, Hilibrand AS, Boden SD, Deyo RA (2006) Surgical vs nonoperative treatment for lumbar disk herniation: the spine patient outcomes research trial (SPORT): a randomized trial. JAMA 296:2441-2450. doi:10.1001/jama.296. 20.2441

71. Whang PG, Lim MR, Sasso RC, Skelton A, Brown ZB, Greg AD, Albert TJ, Hilibrand AS, Vaccaro AR (2008) Financial incentives for lumbar surgery: a critical analysis of physician reimbursement for decompression and fusion procedures. J Spinal Disord Tech 21:381-386. doi:10.1097/BSD.0b013e31814d4e1b

72. Wood KB, Bohn D, Mehbod A (2005) Anterior versus posterior treatment of stable thoracolumbar burst fractures without neurologic deficit: a prospective, randomized study. J Spinal Disord Tech 18(Suppl): S15-S23. doi:10.1097/01.bsd.0000132287. $65702.8 \mathrm{a}$

73. Yi L, Jingping B, Gele J, Baoleri X, Taixiang W (2006) Operative versus non-operative treatment for thoracolumbar burst fractures without neurological deficit. Cochrane Database Syst Rev CD005079

74. Young RF, Post EM, King GA (1980) Treatment of spinal epidural metastases. Randomized prospective comparison of laminectomy and radiotherapy. J Neurosurg 53:741-748

75. Zucherman JF, Hsu KY, Hartjen CA, Mehalic TF, Implicito DA, Martin MJ, Johnson DR, Skidmore GA, Vessa PP, Dwyer JW, Puccio S, Cauthen JC, Ozuna RM (2004) A prospective randomized multi-center study for the treatment of lumbar spinal stenosis with the X STOP interspinous implant: 1-year results. Eur Spine J 13:22-31. doi:10.1007/s00586-003-0581-4

76. Zucherman JF, Hsu KY, Hartjen CA, Mehalic TF, Implicito DA, Martin MJ, Johnson DR, Skidmore GA, Vessa PP, Dwyer JW, Puccio ST, Cauthen JC, Ozuna RM (2005) A multicenter, prospective, randomized trial evaluating the X STOP interspinous process decompression system for the treatment of neuro-genic intermittent claudication: two-year follow-up results. Spine 30:1351-1358. doi:10.1097/01.brs.0000166618.42749.d1 